\title{
Эффективность и безопасность раствора тобрамицина для ингаляций в лечении синегнойной инфекции при муковисцидозе
}

1 - Национальное агентство клинической фармакологии и фармации: 109088, Москва, ул. Угрешская, 2, стр. 8;

2 - Российский государственный медицинский университет: 117997, Москва, ул. Островитянова, 1

Yu.B.Belousov, S.K.Zyryanov, A.V.Sokolov

Efficacy and safety of inhaled solution of tobramycin in treatment of pseudomonal infection in cystic fibrosis

Key words: cystic fibrosis, Pseudomonas aeruginosa, tobramycin, inalations, pharmacokinetics, efficacy, safety.

Ключевые слова: муковисцидоз, Pseudomonas aeruginosa, тобрамицин, ингаляции, фармакокинетика, эффективность, безопасность.

Муковисцидоз - генетическое заболевание с аутосомно-рецессивным механизмом наследования. В США выявлено 30000 больных муковисцидозом, при этом каждый год диагностируется 1000 новых случаев. Муковисцидоз одинаково часто встречается среди мужчин и женщин, при этом представители европеоидной расы более подвержены данному заболеванию. Так, в регистре Американского фонда муковисцидоза в 2008 г. были зарегистрированы 24487 пациентов, из них 89 \% были европеоидами. В > $70 \%$ случаев заболевание диагностируется в возрасте до 2 лет, однако у $10 \%$ пациентов данная патология выявляется в возрасте старше 18 лет [1-3].

Единственным фактором риска развития этой патологии является наследственная предрасположенность. Более чем 10 млн американцев, не подозревая об этом, являются носителями гена муковисцидоза. При условии, что таковыми являются оба родителя, вероятность возникновения заболевания у ребенка равна $25 \%$, вероятность носительства гена муковисцидоза - $50 \%$, а его отсутствия - $25 \%$ [3].

Согласно статистике, носителем данного гена является каждый 30-й житель Европы. В России насчитывается > 1,5 тыс. детей, больных муковисцидозом, - при том, что на каждого зарегистрированного пациента приходится 10 невыявленных [4].

Мутациями единственного рецессивного гена CFTR, муковисцидозного трансмембранного регулятора, в 7-й хромосоме (а их в настоящее время описано > 700) обусловлены различные фенотипы заболевания. Одни мутации в гене CFTR ведут к снижению синтеза белка CFTR из-за незавершенности процессинга РНК, другие - к качественным изменениям мембранных хлорных каналов. Так, вызванное дефектом гена нарушение транспорта хлоридов может быть выявлено в различных органах и тканях: потовых железах, репродуктивной системе, кишечнике, печени, поджелудочной железе, респираторном тракте. В легких, в частности, обусловлен- ное дефектом гена нарушение метаболизма приводит к изменению свойств секрета бронхиального дерева, что снижает его защитные свойства и активность мукоцилиарного клиренса. Патологическое гликозилирование гликоконъюгатов (слизи или клеточной оболочки) может провоцировать обструкцию дыхательных путей и сопровождаться изменением адгезивных свойств эпителия дыхательных путей, что, в свою очередь, приводит к развитию инфекционного процесса [5].

Таким образом, муковисцидоз характеризуется хроническим инфекционным процессом в дыхательных путях и экзокринной панкреатической недостаточностью. Тяжесть заболевания и симптоматика могут варьироваться в зависимости от типа мутации. Только у 10-15 \% пациентов обнаруживаются при рождении признаки заболевания: мекониальный илеус, плохая прибавка веса, расстройства пищеварения вследствие недостаточности панкреатических ферментов. В более старшем возрасте на необходимость диагностики муковисцидоза указывают повторные инфекции дыхательных путей. Кроме того, блокада протоков поджелудочной железы и кишечных желез приведет к возникновению проблем с пищеварением, синдрома мальабсорбции, следствием которых становится задержка физического развития. У подростков и взрослых пациентов, в дополнение к респираторной симптоматике, утолщаются концевые фаланги пальцев кисти, появляются назальные полипы, нередок синусит [6].

У большинства пациентов проблемы респираторного тракта определяют тяжесть течения заболевания. Накопление бронхиального секрета и продуктов распада клеток приводит к развитию бронхиальной обструкции и деструктивным изменениям в легочной ткани. Вследствие сниженной функции мукоцилиарного клиренса и изменения адгезивных свойств дыхательного эпителия к муковисцидозу присоединяется бактериальная инфекция респираторного 
тракта, принимающая хроническое течение. Прогрессирование заболевания сопровождается развитием бронхоэктазов и дальнейшей обструкцией. Легочные осложнения муковисцидоза могут проявиться также в виде спонтанного пневмоторакса.

Прогрессивное снижение легочной функции является ведущей причиной смерти пациентов с муковисцидозом: 90 \% из них погибают вследствие тяжелой дыхательной недостаточности. Известно, что оценка функции внешнего дыхания (ФВД), о которой судят по изменению объема форсированного выдоха за 1-ю с $\left(O Ф B_{1}\right)$, является строгим клиническим предиктором смертности при муковисцидозе. Кроме того, в настоящее время показано, что инфицирование Pseudomonas aeruginosa или Burkholderia серасіа уменьшает продолжительность жизни пациентов с муковисцидозом по сравнению с пациентами, не инфицированными указанными микробными агентами [6].

Бронхоальвеолярное дерево в норме обычно стерильно. Изменение физико-химических свойств мокроты у пациентов с муковисцидозом приводит к возможности персистирования микроорганизмов в нижних отделах дыхательных путей и их инвазии в ткани. В раннем возрасте у пациентов с муковисцидозом наиболее распространены такие микробные агенты, как Staphylococcus aureus и Haemophilus influenzae, затем чаще встречается P. aeruginosa. Указанный микроорганизм обнаруживается в 30 \% случаев при культуральном исследовании мокроты у детей раннего возраста, в 30-40\% - у детей 2-10 лет и в 60-80\% - у подростков и взрослых [7].

Существуют определенные факторы риска развития инфекции, вызванной $P$. aeruginosa: женский пол, гомозиготный генотип $\Delta \mathrm{F} 508$ и наличие изолятов $S$. aureus, обнаруживаемых при культуральном исследовании мокроты [8, 9].

Течение инфекционного процесса, вызванного P. aeruginosa, сопровождается более выраженным снижением показателей ФВД, более высокой частотой госпитализаций и уменьшением ожидаемой продолжительности жизни. Таким образом, инфицирование $P$. aeruginosa играет критическую роль в долгосрочном прогнозе пациентов с легочной формой муковисцидоза, поскольку зачастую сопровождается значительными деструктивными процессами в легочной ткани.

В процессе инфицирования $P$. aeruginosa условно выделяют 3 фазы (табл. 1).
Известно, что отличительной особенностью штаммов $P$. aeruginosa при хронической инфекции является их переход в мукоидную форму, что приводит к резкому снижению эффективности проводимой антибиотикотерапии. На поздних стадиях развития заболевания респираторный тракт колонизируется и другими микроорганизмами, включая B. cepacia, Stenotrophomonas maltophilia и некоторые виды грибов [9].

Исходя из вышесказанного, фармакотерапия пациентов с муковисцидозом должна включать в себя антимикробные препараты, панкреатические ферменты и витамины для улучшения питания. Особое значение современные руководства по лечению муковисцидоза придают устранению инфекционного процесса. Задачами антимикробной терапии при муковисцидозе являются сокращение числа эпизодов легочной инфекции (особенно вызванной P. aerugi$n o s a$, уменьшение количества и вязкости продуцируемой мокроты, предотвращение падения ОФВ и улучшение легочной функции [6].

Антимикробная терапия при муковисцидозе может назначаться эмпирически или на основании предшествующих культуральных исследований. Цель интенсивной антипсевдомонадной терапии предотвращение прогрессирования колонизации микроорганизма и его эрадикации. При этом антибиотики должны быть достаточно безопасными, т. к. могут применяться в течение длительного периода.

Одной из групп антибиотиков, сохраняющей довольно высокую активность в отношении $P$. aeruginosa, являются аминогликозиды (II-III поколений), для которых характерна дозозависимая бактерицидная активность против грамотрицательных микроорганизмов семейства Enterobacteriaceae, а также неферментирующих грамотрицательных палочек ( . aeruginosa, Acinetobacter spp.) и стафилококков (кроме метициллинорезистентных штаммов). Важно, что по отношению к $P$. aeruginosa тобрамицин в 2-4 раза эффективнее гентамицина. Аминогликозиды распределяются во внеклеточной жидкости, включая сыворотку крови, экссудат абсцессов, асцитическую, перикардиальную, плевральную, синовиальную, лимфатическую и перитонеальную жидкость. Антибиотики данной группы способны создавать высокие концентрации в органах с хорошим кровоснабжением: печени, легких, почках, но при этом низкие концентрации отмечаются в мокроте и бронхиальном секрете. Кроме того, специфическая антибактериальная

Таблица 1

Фазы инфицирования P. aeruginosa

\begin{tabular}{|c|c|c|}
\hline 1-я фаза & Начальная & Первое выявление P. aeruginosa при культуральном исследовании \\
\hline 2-я фаза & Ранняя колонизация & $\begin{array}{l}\text { Периодическое выявление немукоидной формы патогена в мокроте при отсутствии антител в крови; } \\
\text { обычно период длится } 12 \text { мес. }\end{array}$ \\
\hline \multirow[t]{4}{*}{ 3-я фаза } & Хроническая инфекция & $\begin{array}{l}\text { Обнаружение патогена при культуральном исследовании мокроты с сопутствующим быстрым ростом титра } \\
\text { сывороточных антител к P. aeruginosa; }\end{array}$ \\
\hline & & развитие эндобронхита; \\
\hline & & частые эпизоды обострений инфекционного процесса; \\
\hline & & $\begin{array}{l}\text { состояние пациента характеризуется эскалацией симптомов: увеличением частоты и интенсивности кашля, } \\
\text { продукцией мокроты, появлением крови в мокроте, уменьшением толерантности к физическим нагрузкам, } \\
\text { снижением ОФВ } 1 \text {, уменьшением сатурации крови кислородом }\end{array}$ \\
\hline
\end{tabular}


активность аминогликозидов уменьшается в нижних дыхательных путях вследствие связывания антибиотика с экстрацеллюлярными макромолекулярными соединениями (ДНК, муцин), а также наличествующими в высоких концентрациях бивалентными катионами [10].

Целью исследования T.F.Moriarty et al. [11] было определение способности антибиотиков, системно вводимых для лечения обострения бронхолегочного процесса больным муковисцидозом, достигать концентраций, необходимых для подавления бактериального роста в очаге инфекции. Изучалась мокрота 14 пациентов, получавших внутривенно цефтазидим (9 г в сутки) и тобрамицин (8 мг/кг в сутки). Содержание обоих препаратов определялось с помощью метода высокоэффективной жидкостной хроматографии (ВЭЖХ). Патогены, выделенные у пациентов, изучались на чувствительность к тобрамицину и цефтазидиму путем измерения минимальной ингибиторной концентрации (МIC). Пиковая концентрация препаратов составила 3,8 и 11,8 соответственно. МІС при применении цефтазидима достигалась только в $16 \%$ образцов мокроты. При использовании тобрамицина МIC не была обнаружена ни в одном случае. Таким образом, внутривенное введение тобрамицина или цефтазидима в дозах, рекомендованных для лечения обострений бронхолегочного процесса при муковисцидозе, не приводит к достижению необходимого уровня этих препаратов в мокроте.

Аминогликозиды практически полностью экскретируются путем клубочковой фильтрации. В клетках проксимальных канальцев они взаимодействуют с щеточной каймой, что нарушает нормальную реабсорбцию белков в канальцах и развитие нефротоксической реакции. Клинически аминогликозид-индуцированная нефротоксичность характеризуется асимптоматическим подъемом уровня сывороточного креатинина через 5-10 дней после начала лечения и возвращается к норме в течение нескольких дней после прекращения терапии. Обычно у пациентов не наблюдается олигурии.

Повреждения клубочков во время терапии аминогликозидами возникают у 3-10 \% взрослых пациентов и у 0-10\% новорожденных. Повреждения канальцев наблюдались у 50-100 \% как взрослых, так и новорожденных, получавших системную терапию аминогликозидами, несмотря на индивидуальный терапевтический мониторинг лекарственного препарата.

Факторами риска развития нефротоксичности являются высокая пиковая и остаточная концентрация антибиотика, длительная терапия (> 10 дней), сопутствующие состояния (гипоксия, дистресс-синдром, сепсис, электролитные нарушения и т. д.), взаимодействие с другими лекарственными средствами (нестероидными противовоспалительными средствами, ванкомицином, фуросемидом). Системное применение аминогликозидов кроме нефротоксичности может сопровождаться ототоксичностью, вестибулотоксичностью, нервно-мышечным блоком [12].
Одним из способов повышения эффективности применения аминогликозидов, в частности тобрамицина, и снижения риска развития неблагоприятных побочных реакций является ингаляционное введения препаратов. На сегодняшний день раствор для ингаляций тобрамицина - Тоби (Novartis $A G$, Швейцария) является единственным ингаляционным антибиотиком, рекомендованным Фондом муковисцидоза и Американской академией педиатрии для лечения инфекции P. aeruginosa у пациентов с муковисцидозом [1-3]. Он представляет собой раствор тобрамицина, специально разработанный для ингаляций посредством небулайзера, с соответствующими осмолярностью, $\mathrm{pH}$, концентрацией и отсутствием консервантов, что предотвращает негативное влияние раствора на слизистую оболочку. Это единственный ингаляционный антибиотик, одобренный FDA для лечения синегнойной инфекции у пациентов с муковисцидозом старше 6 лет.

Благодаря ингаляционному введению большая часть действующего вещества концентрируется в дыхательных путях. Молекулы тобрамицина являются катионами, которые не полностью взаимодействуют с эпителиальными мембранами. Биодоступность раствора препарата может изменяться из-за производительности небулайзера и особенностей легочной патологии.

Спустя 10 мин после введения 1-й дозы (300 мг) тобрамицина его концентрация в мокроте составляет в среднем 1237 мкг/г (в диапазоне от 35 до 7414 мкг/г). Вещество не накапливается в мокроте: через 20 нед. от начала терапии его средняя концентрация в мокроте спустя 10 мин после ингаляции составляет 1154 мкг/г (в диапазоне от 39 до 8085 мкг/г). Через 2 ч после ингаляции средняя концентрация тобрамицина в мокроте снижается на $14 \%$ от этого уровня.

Средняя сывороточная концентрация тобрамицина через 1 ч после ингаляционного введения дозы 300 мг у пациентов с муковисцидозом составила 0,95 мкг/мл. После 20 нед. лечения раствором для ингаляций этот показатель составлял 1,05 мкг/мл важно, что остаточная концентрация, свидетельствующая о степени кумуляции аминогликозидов и позволяющая контролировать безопасность терапии, для тобрамицина должна быть $<2$ мкг/мл.

Период полураспада тобрамицина после внутривенного введения составляет 2 ч. Предполагается, что элиминация из сыворотки тобрамицина, поступившего ингаляционным путем, аналогична его элиминации при внутривенном введении и реализуется, главным образом, за счет клубочковой фильтрации. Выведение после ингаляции тобрамицина, не поступившего в кровь, осуществляется при откашливании мокроты [12].

Рекомендуется следующая схема применения: ингаляции через небулайзер в дозе 300 мг 2 раза в день в течение 28 дней с последующим 28-дневным перерывом.

Эффективность применения препарата была подтверждена целым рядом исследований. Так, уста- 
новлено, что ингаляционное применении тобрамицина сопровождается улучшением ФВД [13]. На момент окончания 24-недельного исследования показатель ОФВ 1 был статистически достоверно выше в группе пациентов, получавших ингаляции тобрамицина, по сравнению с группой плацебо [13, 14]. В другом исследовании по его окончании на 96-й нед. ОФВ 1 у пациентов, лечившихся ингаляциями изучаемого препарата, был на 14,34 \% выше показателя, полученного на момент начала лечения [13].

Эффективность применения раствора тобрамицина подтверждается также снижением длительности госпитализаций на $26 \%$, а также уменьшением средней длительности госпитализации на $37 \%$ по сравнению с пациентами, получавшими плацебо. Важно подчеркнуть, что использование данной формы препарата сопровождается повышением качества

Ингаляционное применение тобрамицина на 36 \% снижает потребность в парентеральном назначении других антисинегнойных антибиотиков. О его эффективности свидетельствует и тот факт, что по окончании 96 нед. терапии масса тела пациентов, получавших препарат, была на $11 \%$ выше по сравнению с исходной [13].

Использование ингаляций тобрамицина в терапии синегнойной инфекции у пациентов с муковисцидозом приводит к уменьшению содержания $P$. aeruginosa в мокроте. Так, в группе пациентов, получавших препарат в течение трех 28-дневных циклов, плотность содержания микроорганизма понизилась на $0,8 \log _{10} \mathrm{KOE}$ на 1 г мокроты, в то время как аналогичный показатель в группе плацебо сократился на $0,3 \log _{10}$ KOE на 1 г мокроты [14].

Применение раствора тобрамицина для ингаляций достаточно безопасно. Из побочных эффектов чаще всего встречаются охриплость голоса (13\% vs 7 \% в группе плацебо), шум в ушах (3\% vs $0 \%$ соответственно). Все эпизоды шума в ушах были преходящими и не сопровождались снижением слуха, по данным аудиограммы $[13,14]$.

На сегодняшний день на фармацевтическом рынке России представлены 2 препарата тобрамицина в виде раствора для ингаляций: Тоби ${ }^{\circledR}-$ раствор для ингаляций, содержащий тобрамицин в количестве 300 мг на 5 мл ("Новартис Фармасьютикалз ЮК Лтд, Хоршем", Великобритания), и Брамитоб - раствор для ингаляций, содержащий активное вещество тобрамицин в количестве 300 мг на 4 мл ("Голопак Ферпакунгстехник ГмбХ, Зульцбах-Лаурен", Германия). Bce приведенные выше данные по эффективности и безопасности применения раствора тобрамицина для ингаляций в полной мере справедливо относить только к препарату Тоби, поскольку они были получены в клинических исследованиях, в которых изучалось именно это лекарственное средство.

Учитывая большой интерес клиницистов к новым препаратам для лечения муковисцидоза и оценке их свойств по сравнению с лекарственными средствами, уже представленными на рынке, в испытательной лаборатории Национального агентства клинической жизни пациентов [15].

фармакологии и фармации был проведен фармакохимический анализ лекарственных форм препарата тобрамицина указанных выше производителей. Изучались 2 образца с целью выяснения их различий или определения фармацевтической эквивалентности:

1) Тоби - раствор для ингаляций, 300 мг / 5 мл, 56 ампул ("Новартис Фармасьютикалз ЮК Лтд, Хоршем", Великобритания), серия Х0020/3, произведен в мае 2008 г., годен до апреля 2011 г;

2) Брамитоб - раствор для ингаляций, 300 мг / 4 мл, 56 ампул ("Голопак Ферпакунгстехник ГмбХ, Зульцбах-Лаурен", Германия), серия ID051, произведен в апреле 2008 г., годен до апреля 2010 г.

Очевидно, что допустимый срок хранения препарата Брамитоб в 1,5 раза короче, чем у Тоби. Выявленные различия в сроках годности могут косвенно свидетельствовать о меньшей стабильности субстанции, использовавшейся при производстве препарата Брамитоб.

Чтобы оценить процесс деградации субстанции и ее чистоту, исследовалось количественное содержание посторонних примесей в представленных препаратах. Сравнивали площади пиков на хроматограммах дериватизированных испытуемых растворов с площадью пика тобрамицина на хроматограмме дериватизированного стандартного образца, определенных методом ВЭЖХ. После проведенных вычислений получили значения содержания примесей относительно содержания тобрамицина, приведенные в табл. 2.

Таким образом, результаты фармакохимического анализа свидетельствуют о том, что количество посторонних примесей в препарате Брамитоб в 1,83 раза выше, чем в препарате Тоби.

Оценить клиническую значимость выявленного результата достаточно сложно. Тем не менее зачастую увеличение содержания посторонних примесей сопровождается изменением (не в лучшую сторону) профиля безопасности препарата.

При исследовании эквивалентности антибактериальных препаратов важно учесть все составляющие данного понятия. Поскольку значительная часть химиотерапевтических средств выпускается

Таблица 2

Результаты определения содержания посторонних примесей в препаратах Тоби и Брамитоб

\begin{tabular}{|c|c|c|c|}
\hline $\begin{array}{l}\text { Посторонние } \\
\text { примеси }\end{array}$ & $\begin{array}{c}\text { Нормы по } \\
\text { нд 42-15007-07, \% }\end{array}$ & $\begin{array}{l}\text { Тоби, } \\
\%\end{array}$ & $\begin{array}{c}\text { Брамитоб, } \\
\%\end{array}$ \\
\hline Примесь A & $\leq 0,25$ & 0,1 & 0,2 \\
\hline $\begin{array}{l}\text { Деокси- } \\
\text { стрептамицина } \\
\text { каносаминид }\end{array}$ & $\leq 0,3$ & 0,19 & 0,25 \\
\hline Неамин & Норма отсутствует & 0,02 & 0,02 \\
\hline Небрамин & $\leq 0,4$ & 0,02 & 0,1 \\
\hline Канамицин В & Норма отсутствует & 0,09 & 0,09 \\
\hline $\begin{array}{l}\text { Единичная } \\
\text { неидентифициро- } \\
\text { ванная примесь }\end{array}$ & $\leq 0,1$ & Не обнаружена & $\begin{array}{l}0,09 \\
0,02\end{array}$ \\
\hline $\begin{array}{l}\text { Сумма неиденти- } \\
\text { фицированных } \\
\text { примесей }\end{array}$ & $\leq 0,2$ & Отсутствуют & 0,11 \\
\hline Итого & & 0,42 & 0,77 \\
\hline
\end{tabular}


в лекарственных формах для парентерального введения или для ингаляционного применения, а биодоступность в данной ситуации не изучается, анализ фармацевтической эквивалентности обязателен. Кроме того, при изучении химической идентичности 2 лекарственных средств немаловажно выявить микробную контаминацию, посторонние частицы, продукты разрушения, остатки растворителя, а также загрязнение неорганическими веществами, поскольку все вышеуказанные посторонние примеси могут представлять потенциальную угрозу для здоровья пациента. Различные твердые частицы постоянно присутствуют в окружающей среде - даже в асептических условиях. Загрязнение лекарственных веществ может произойти во время их производства, транспортировки или хранения, а также при непосредственном использовании в клинических условиях, например при вскрытии ампулы возможно попадание частиц стекла, резины или пластика, из которых изготовлены пробки флаконов или шприцы. Наличие примесей, особенно в препаратах для парентерального использования, признается чрезвычайно опасным. Твердые микроскопические частицы примесей могут приводить к развитию нежелательных реакций различной тяжести - от скрытых легочных гранулем, локальных инфарктов в тканях до тяжелых дыхательных расстройств и летальных исходов. Неидентифицируемые примеси могут непредсказуемо изменять спектр возникающих неблагоприятных побочных реакций. В связи с этим особый интерес представляют работы по изучению фармацевтической эквивалентности оригинальных и воспроизведенных антибактериальных средств.

Различия в количественном содержании примесей достаточно часто выявляются при сравнении оригинального и генерических антибактериальных средств. Такие различия были выявлены для препаратов цефтриаксона [16], цефотаксима [17, 18], кларитромицина [19]. При исследовании препаратов кларитромицина у 24 из 40 изученных образцов был превышен рекомендованный компанией-производителем оригинального лекарственного средства 3\%-ный лимит посторонних примесей и порог содержания (> 0,8 \%) 6,11-ди-О-метил-эритромицина А - вещества, отвечающего за возникновение неблагоприятных побочных реакций.

Таким образом, комплексная оценка результатов клинических исследований и профиля безопасности и данные сравнительного изучения фармакохимических свойств растворов тобрамицина для ингаляций, представленных на фармацевтическом рынке России, позволяют сделать вывод о доказанной клинической эффективности и безопасности в лечении синегнойной инфекции у пациентов с муковисцидозом и высоком качестве раствора препарата Тоби ${ }^{\circledR}$.

\section{Литература}

1. Cystic fibrosis foundation: About cystic fibrosis. www.cff.org

2. Cystic Fibrosis Fact Sheet 2006. www.lungusa.org

3. American Lung Association (ALA). Lung Disease Data: 2008. Available at: www.lungusa.org. Accessed on June 2008.
4. http://www.cf-rf.ru/content/ru/about_mucoviscidosis.html доступно: 03.2010.

5. Davies J.C., Alton E.W., Bush A. Cystic fibrosis. Brit. Med. J. 2007; 335: 1255-1259.

6. Flume P.A., S'Sullivan B.P., Robinson K.A. et al. Cystic fibrosis pulmonary guidelines. Chronic medication for maintenance of lung health. Am. J. Respir. Crit. Care Med. 2007; 176: 957-969.

7. Dopfer R., Brand P., Mullinger B. et al. Inhalation of tobramycin in patient with cystic fibrosis: comparison of two methods. J. Physiol. Pharmacol. 2007; 58 (suppl. 5): 141-154.

8. Maselli J.H., Sontag M.K., Norris J.M. et al. Risk factors for initial acquisition of Pseudomonas aeruginosa in children with cystic fibrosis identified by newborn screening. Pediatr. Pulmonol. 2003; 35: 257-262

9. Gibson R.L., Emerson J., McNamara S. et al. Significant microbiological effect of inhaled tobramycin in young children with cystic fibrosis. Am. J. Respir. Crit. Care Med. 2003; 167: 841-849.

10. Страчунский Л.С., Белоусов Ю.Б., Козлов С.Н. (ред.). Практическое руководство по антиинфекционной химиотерапии: 3-е изд.; 2008.

11. Moriarti T.F. et al. Intrapulmonary concentrations of tobramycin and ceftazidime archived after intravenous administration for the treatment of cistic fibrosis lung infections. J. Cyst. Fibros. 2006: 5 (suppl. 1); S20.

12. Гуревич К.Г., Белоусов Ю.Б. Клиническая фармакокинетика. М.: Литтерра; 2005.

13. Bowman C.M. The long-term use of inhaled tobramycin in patients with cystic fibrosis. J. Cystic Fibrosis. 2002; 1: s194-s198

14. Ramsey B.W., Pepe M.S., Quan J.M. et al. Intermittent administration of inhaled tobramycin in patients with cystic fibrosis. N. Engl. J. Med. 1999; 340: 23-30.

15. Quittner A.L., Buи A. Effects of tobramycin solution for inhalation on global ratings of quality of life in patients with cystic fibrosis and $P$. aeruginosa infection. Pediatric. Pulmonol. 2002; 33: 269-276.

16. Ламберт П.А., Конвей Б.Р. Сравнение фармацевтического качества генерических препаратов цефтриаксона и роцефина. Клин. микробиол. антимикроб. химиотер. 2004; 6 (3): 260-272.

17. Wetterich U., Mutschler E., Rangoonwala R. Comparative quality assurance investigations of claforan and cefotaxime generics from India in respect to particulate matter. Proceedings of the 20th International Congress on Chemotherapy. Sydney, Australia, June 29-July 3. 1997.

18. Lehr H.-A., Brunner J., Rangoonwala R., Kirkpatrick C.J. Particulate matter contamination of intravenous antibiotics aggravates loss of functional capillary density in post ischemic striated muscle. Am. J. Respir. Crit. Care Med. 2002; 165: 514-520.

19. Nightingale C.H. A survey of the quality of generic clarithromycin product from 13 countries. Clin. Drug Invest. 2000; 19: 293-305.

\section{Информация об авторах}

Белоусов Юрий Борисович - д. м. н., член-корр. РАМН, проф., зав. кафедрой клинической фармакологии РГМУ, президент ООО "Национальное агентство клинической фармакологии и фармации"; тел.: (499) 261-65-10; e-mail: belouspharma@mtu-net.ru

Зырянов Сергей Кенсаринович - д. м. н., проф. кафедры клинической фармакологии РГМУ, директор медицинского департамента ООО "Национальное агентство клинической фармакологии и фармации"; тел.: (499) 261-25-90; e-mail: serguei_kensarin@hotbox.ru

Соколов Андрей Владимирович - д. б. н., руководитель испытательной лаборатории ООО "Национальное агентство клинической фармакологии и фармации", тел.: (495) 933-95-95; e-mail: andrey.v.sokolov @nacph.ru 


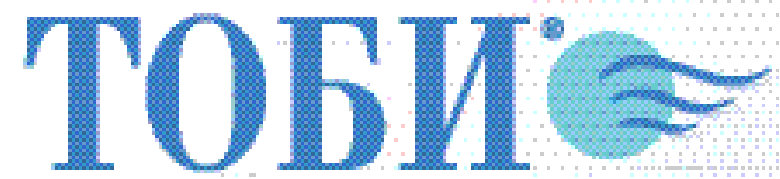

ТОбрамИМИН

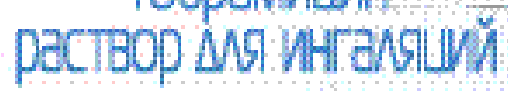

Жизненно

важный

препарат

\section{для пациентов}

с муковисцидозом*
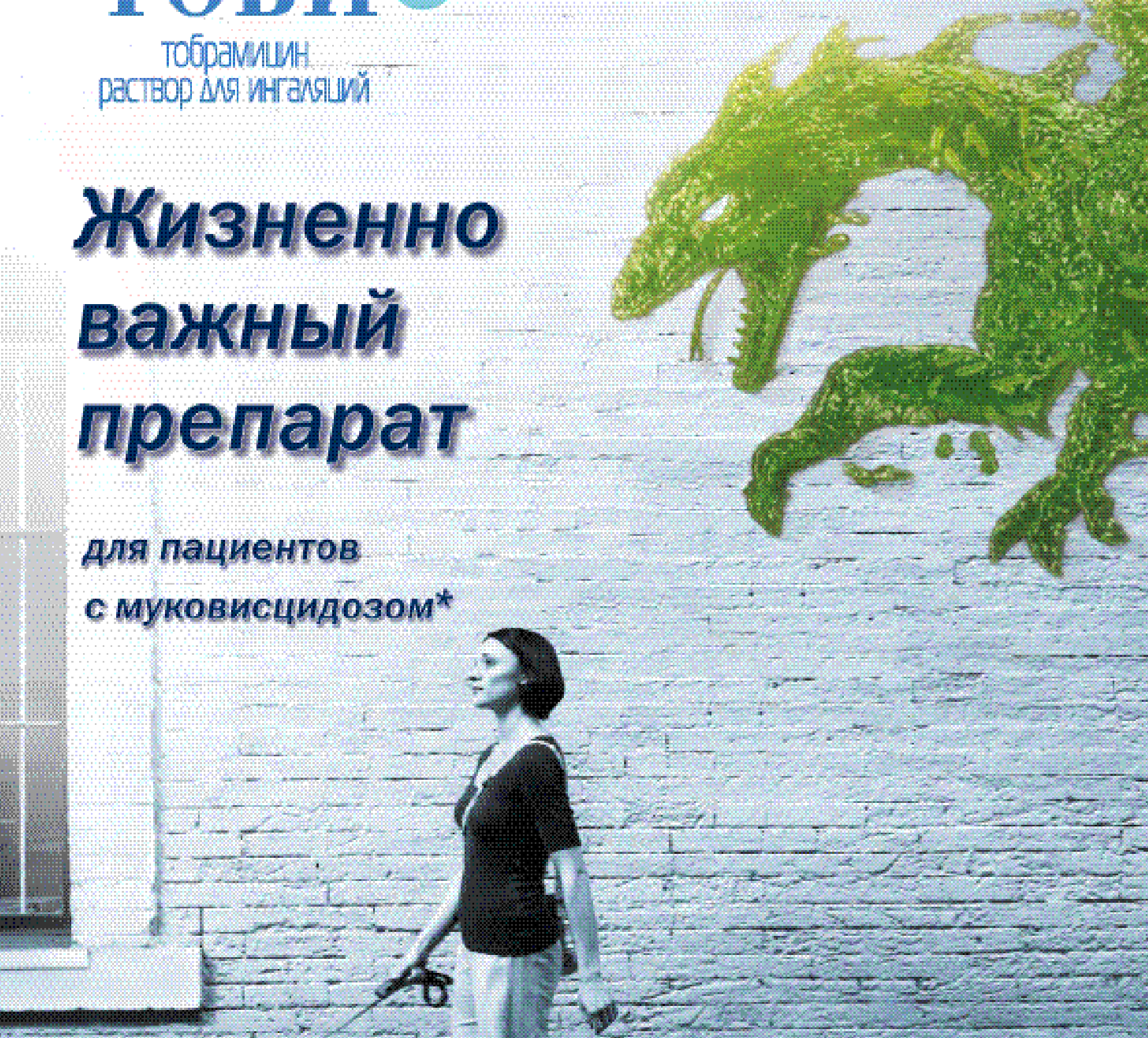

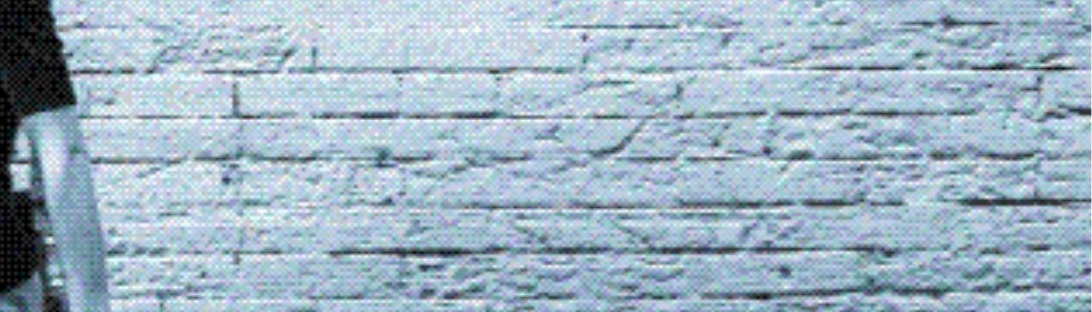

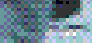

$0=2 x+2=$

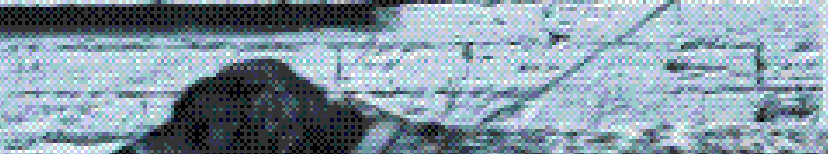

$203 x-4 \sin ^{2}$ il

- p.

$5 \sqrt{6}$

the

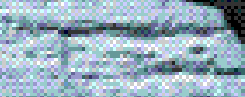

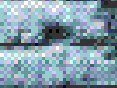

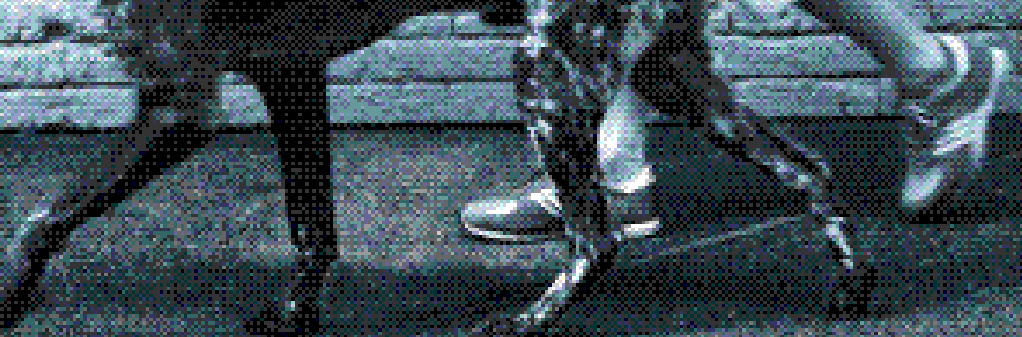

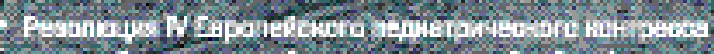

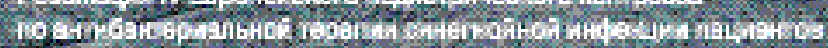

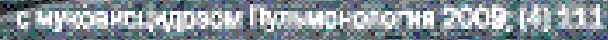

(b) NOVARTIS 